Contents lists available at Journal Redwhitepress
Journal of Educational and Learning Studies
ISSN: 2655-2760 (Print) ISSN: 2655-2779 (Electronic)
Journal homepage: http://journal.redwhitepress.com/index.php/jles

\title{
Using digital reading in ESL Malaysian primary classrooms: the strengths and the shortcomings from the learners' perspectives
}

\author{
Nurul Qistina Baharuddin ${ }^{1}$, Harwati Hashim ${ }^{2 *}$ \\ ${ }^{12}$ Faculty of Education, Universiti Kebangsaan Malaysia, Malaysia
}

\begin{tabular}{|c|c|}
\hline Article Info & ABSTRACT \\
\hline Article history: & $\begin{array}{l}\text { This paper discusses the relevance of digital reading in Malaysian education } \\
\text { setting, especially in second language acquisition. This paper provides some }\end{array}$ \\
\hline $\begin{array}{l}\text { Received Jan } 12^{\text {th }}, 2020 \\
\text { Revised Feb } 25^{\text {th }}, 2020 \\
\text { Accepted Mar } 26^{\text {th }}, 2020\end{array}$ & $\begin{array}{l}\text { definitions on digital reading before further elaborates the underlying } \\
\text { theoretical framework, TAM model (1989). Later on, the strengths and the } \\
\text { shortcomings of digital reading are presented to provide adequate information } \\
\text { on the research topic. } 30 \text { Level } 2 \text { pupils from a primary school in a state in }\end{array}$ \\
\hline Keyword: & $\begin{array}{l}\text { Malaysia had participated in the survey and ten of them were randomly } \\
\text { selected for the interview session. This research found that ESL primary }\end{array}$ \\
\hline Digital reading & $\begin{array}{l}\text { learners enjoy digital reading as it is useful and interesting to be explored in } \\
\text { their language learning. Despite the existing limitation due to lack of related }\end{array}$ \\
\hline ESL & facilities at school, digital reading seems to be a convincing approach for ESL \\
\hline $\begin{array}{l}\text { Second language acquisition } \\
\text { Strengths }\end{array}$ & learners in language mastery. It is hoped that this paper initiates more research \\
\hline Shortcomings & \\
\hline
\end{tabular}

(C) 2020 The Authors. Published by Redwhitepress.

This is an open access article under the CC BY-NC-SA license

(https://creativecommons.org/licenses/by-nc-sa/4.0/

\section{Corresponding Author:}

Harwati Hashim,

Faculty of Education, Universiti Kebangsaan Malaysia

Email: harwati@ukm.edu.my

\section{Introduction}

The role of English as the second language in Malaysia has been highlighted in recent years due to the implementation of the Malaysia National Educational Blueprint (NEB) (2013-2025). One of the student aspirations in the document is bilingual proficiency, in which informs the need for the young learners to successful second language acquisition (SLA). This is further elaborated in Shift 2 of the 11 shifts which encourages the pupils to learn English as a preparation to a globally-driven world. (Ministry of Education 2013). To achieve this, the Ministry of Education has outlined the curriculum in a way that equips the learners with all the language skills. Above all, reading is considered to be crucial in language acquisition as it imparts the knowledge content from the text to the readers. The current NEB also proposes the idea of selfindependent learners. (Ministry of Education 2013). Dobler (2015) supports this notion by indicating the need of the learners to have the characteristics of 21st century learners. They should be involved in active, selfdirected and meaningful learning where they can monitor and assess their knowledge input and output. With the different varieties of learning materials offered, learners can be in charge of their own individualized learning. (Hashim, Md. Yunus, Embi, Mohamed Ozir, 2017). It is important to provide necessary support and opportunities for them to be independent learners, so digital reading is rather a good alternative for this type of learning.

The term 'digital reading' is coined in the early millennial years with the mushrooming existence of Internet access and high technology software. It starts with the different text forms and variety of reading tools 
which encourage the exploration of digital literacy. (Singer and Alexander 2017). E-books, e-journals and a lot more interactive online applications have been introduced to society to fit the millennial calls for the hightechnology trends and lifestyles. These tools provide easy access to almost everything - from leisure text to educational articles, just at one click. Another point of view made on digital reading is it involves 'reading text on a display screen.' (Kurata, Ishita, Miyata, Minami 2016). There is no standard format for this digital reading as long as readers can read the online text comprehensively.

An effective digital reading offers the integration of technology and content knowledge into the text read. (Ciampa 2016). This is to prepare the readers with 21st century skills as they retrieve the information from a diverse range of online learning tools. As a matter of fact, learners are made aware of the literacy skills needed in digital reading in order to encourage independent learning. Due to the current trend of utilizing emails, news sites and other online materials, a lot of people have moved from text-printed dependent to texton-screen reading. (Kurata, Ishita, Miyata, Minami 2016) It is an unstoppable change to the global, high tech world thus making digital reading another wise option for learning and teaching for daily basis. To support this, Gartner (2011) and Hashimoto (2011) have conducted their respective studies and conclude that more people are resulted in spending 'almost equal time or double the time on digital reading as they read the printed text.' (Kurata, Ishita, Miyata, Minami 2016). It shows the preference of today's generation towards digital literacy over the conventional text print.

Another major factor of the widespread use in digital reading is the requirement for digital international and national assessments for the learners. (Singer and Alexander 2017). One of the reasons is because of the low cost and easy access to the related websites. A study done by Kurata, Ishita, Miyata and Minami (2016) found that about majority of the respondents agreed that $70 \%$ of their reading time was spent on digital media. As long as the text carries meaningful content, it is no doubt that digital reading has taken up the role of printed text materials. The objective of the research is to explore learners' perspectives on the strengths and the shortcomings of using digital reading in ESL Malaysian primary school classroom.

\section{Theoretical basis}

From the topic of interest, one of the underlying theories in digital reading is Technology Acceptance Model (TAM) by Davis (1989). This theory is introduced to examine the use and the acceptance of any technology by the target users. (Surendran n.d.). It is relevant to be referred to as digital reading is considered the current trend among the learners and educators, especially in this millennial era. The theory works as Figure 1.0 shown below.

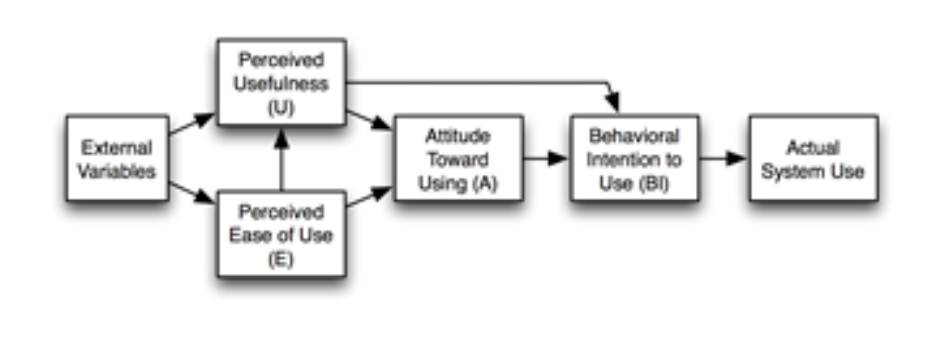

Figure 1. Research Framework

TAM model is used in all over the world in explaining and describing the process of delivering the knowledge content through the use of ICT interface. (Masrom 2007). In this context, Davis further elaborate the three factors that influence the user's motivation in using the technology, which are perceived usefulness, perceived ease of use and attitude toward using. (Chultur 2009). These factors are controlled by the external variables, such as social, cultural and political factors. Every component plays their roles in directing towards the actual use of the technology, which is also determined by the behavioural intention to use. The behavioural intention to use is the level to which determines the possibilities of the user to employ the actions. (Surendran n.d.)

This theory is good at examining the acceptance of digital reading in language classroom. Evaluation on the acceptance of other technology and inventions had been conducted in previous years, thus proving this theory is a reliable foundation.

\section{Strengths}

Digital reading has been utilized both in the classroom and outside the classroom. As more people begin to recognize the use of it worldwide, reading through digital media has proven to benefit the learning and teaching society at large. There are a lot of positive impacts that it brings in the education system, which will later be discussed in the next part of the writing. 
Digital reading has made the text reachable and accessible, in terms of costing and physical. (Baron 2017). As the readers go through the text, they will be able to retrieve the e-book with a low price rather than buying the physical book. Some of the publications have been made free to be accessed with certain affordable conditions like signing up for the website, sharing the article to other friends and giving a brief feedback upon reading the whole text. As it reduces the storage space and keep the text online, readers have to be IT-savvy to be able to retrieve the text. A 21st century lesson that utilizes digital tools has surely prepared the learners with the ICT skills needed for better learning experiences.

Learners are proven to be good at multitasking when they are given onscreen reading tasks. (Baron 2017). As they are browsing through the text, they can open new tabs and other application at the same time. For example, when they encounter difficult words in the reading text, they can open their digital dictionary and look for the meaning instantly. It somehow facilitates their learning in a way that helps them to make meaning of the text comprehensively. (Razali, Hashim \& Md. Yunus, 2019). While waiting for the website to be fully downloaded, learners can complete other offline tasks and still keep on track with their reading pace. This provides better learning experiences to them with motivation and interests in exploring the language using digital tools and media. (Morshidi, Embi \& Hashim, 2019).

The adjustable features and user-friendly format of digital tools have been another convincing factor that leads to readers' preference to digital reading. The readers can explore the text by fully utilizing the tools provided in the application or software. E-textbook offers such editing tools that can edit the font sizes, highlight the points needed and post video clips that are related to the subject content. (Dobler 2015). These customization tools are not presentable in printed text, thus making digital reading a more supporting learning media to 21 st century learning. With these features and layout in digital media, readers are not restricted to the conventional printed text and they are able to make full use of the available learning tool.

\section{Shortcomings}

Despite the benefits offered in digital reading, there are some shortcomings and flaws identified. The learners' reading behaviour is largely influenced by their preferences to the learning media. From a study conducted in 2016, it is clearly seen that readers are prone to like printed text more than onscreen text. (Kurata, Ishita, Miyata, Minami 2016). However, no generalization should be imposed on the subject matter as it may vary according to the location, accessibility and situation of the society based on different areas.

Based on a survey done by Baron (2017), respondents agree that they have difficulties in comprehending the text when they carry out digital reading. As they use less comprehension strategies in reading the text, it is observed that their reading scores are not as good as when they are reading printed text. Those comprehension strategies like note-taking and bookmarking support the reading processes and brings meaningful content and context to the readers. Kaufman and Flanagan (2016) further support the point by indicating the one of the findings in their research. Most participants managed to get more abstract questions correct in printed reading as compared to digital reading. However, it is proven that they were able to tackle concrete questions better in onscreen text.

In comparing both digital and printed reading, the physical touch of the text is rather be seen as more realistic. (Baron 2017). Digital reading encourages multi-tasking among the readers, which makes them less observant and attentive to the text. It is learnt that on screen text brings possible distractions and misuse to the learners while they are on task. (Nor Pazilah, Hashim \& Md. Yunus, 2019). They tend to feel they are merely reading on surface as they have access to other applications that support the text. For example, if readers are to read for quotes, they are more likely to skim and scan the whole text and scroll through the text to source the reference. In fact, digital layout and features are great distraction to the readers in diverting them from grasping the knowledge content. (Paul, 2014). By doing so, readers cannot focus and give their full attention to text as 'they are switching so often during the text processing.' (Singer and Alexander 2017). It would be different if they have the text printed and they can explore the text in different ways. There is no such way the readers can get the gist of the text, provided they really go through every words and sentences in the text. . The time constraint for them to use learning media and tools during the lesson also sets another limitation in utilizing the technology in the text during ESL learning. (Hashim \& Yunus, 2012). This explains the reality of the learners' difficulty in accessing digital texts for their reference.

Limited and restricted teacher training in using digital reading in language lesson is another misleading factor in this study. Ciampa (2016) argues the need for sufficient and supportive professional learning courses to be conducted to the teachers. It is part and parcel of the learning and teaching experiences as teachers should exhibit related knowledge and skills in digital reading in order to conduct effective 21st century language learning. (Dobler 2015). With regards to their perceptions towards using technology, it is learnt that 
half of the participants (51\%) feel uncomfortable in using ICT in their lesson. (Ciampa 2016). This shows a great concern especially to the teachers in utilizing digital reading to the fullest.

\section{Method}

This research was conducted using a mixed method of structured survey and semi-structured interviews. Harris and Brown (2010) suggest that by combining these two will provide convincing data collection to the research, thus generating the most accurate and precise result. However, in this research, survey was used in the beginning of the session to introduce the issue to the participants before they started using digital reading during ESL lessons. After their fifth lessons, ten participants were randomly selected from the same class to be interviewed on their perceptions of using digital reading in English lessons.

The research was conducted in a primary school in Penang. The instrument used in the research was the survey and the interview. The survey was used to identify the participants' prior knowledge and experiences of the use of digital reading in their ESL lessons. It was adapted from a survey by Syaputri and Trilestari (2017) and be made simplified to cater the level of primary school pupils. A class of 30 mixed-ability pupils participated in the survey and ten of them were randomly selected for the interview session. They were of Level 2 pupils who were involved in ESL lessons four times in a week. They were selected as they had not experienced using digital reading during the lessons before. Their English teacher first conducted the survey. After their fifth lessons using digital reading, the researcher interviewed ten of the participants to get detailed responses to support the findings.

\section{Results and Discussions}

Data for the results are derived from the survey form and the interview transcription. The data from survey form and interview transcriptions were analysed to identify the pupils' perception on using digital reading in their ESL lessons.

Raw production of their responses in the survey was summarized in Table 1. The table recorded the participants' responses based on the choice of answers provided in the survey.

From the table shown, all the participants' responses were collected to identify their prior knowledge and experiences in using digital reading. A few assumptions can be made from their responses. The first three items of the questionnaires describe the respondents' reading habits. Ten out of thirty participants stated they like reading. In the next item, eleven respondents admitted that they read for entertainment as compared to other reading purposes. A large number of them (13) stated that they read for one to two hours daily. In these items, the researcher finds that the participants are largely reading for leisure for a short period of time. It describes the reading habit of the participants in general.

Item 4 and 5 showed the participants' preferences on the usage of either printed or digital reading. Almost half of the respondents (12 for printed and 15 for digital) used both reading throughout the day. However, only 9 of them initiated that they know what digital reading is. The rest of the respondents were not aware of the terms 'digital reading' as they have never encountered the terms before.

Item 7 to 9 outline the use of digital reading among the participants. 14 respondents admitted that they spent one to two hours on screen reading. From the responses, 15 participants stated that they use other types of digital reading materials, apart from e-mails, e-books, and Powerpoint presentations. 12 respondents also indicated that they use mobile phones in digital reading. The data show resemblance in the time spent for reading in both digital and printed. The participants showed a great understanding in identifying the types of materials used as half of them stated others. They might refer to different applications and software which are not stated in the questionnaire.

The final item of the questionnaires inquires the respondents on their preferences of using either digital or printed reading in reading English. 18 respondents showed their interest in reading on screen. The researcher thinks it is best to end the questionnaires by asking the participants' preferences on both digital and printed reading. It leaves them with a choice based on their prior experiences in using digital and printed reading.

The questionnaires manage to provide an overview of the learners' prior perspectives on using digital reading. The information later guides the researcher in analysing the interview transcriptions. 
Using digital reading in ESL Malaysian primary classrooms : the strengths and the shortcomings from the learners' perspectives

\begin{tabular}{|c|c|c|c|c|c|}
\hline No. & Item & \multicolumn{4}{|c|}{ Responses } \\
\hline \multirow[t]{2}{*}{1.} & \multirow[t]{2}{*}{ Do you like reading? } & \multicolumn{2}{|c|}{ Yes } & \multicolumn{2}{|c|}{ No } \\
\hline & & \multicolumn{2}{|c|}{10} & \multicolumn{2}{|c|}{20} \\
\hline \multirow[t]{2}{*}{2.} & \multirow{2}{*}{$\begin{array}{l}\text { What is the purpose } \\
\text { of your reading? }\end{array}$} & information & entertainment & knowledge & others \\
\hline & & 7 & 11 & 6 & 6 \\
\hline \multirow[t]{2}{*}{3.} & \multirow{2}{*}{$\begin{array}{l}\text { How many hour(s) } \\
\text { do you spend } \\
\text { reading in a day? }\end{array}$} & $<1$ hour & $1-2$ hours & $2-4$ hours & $>4$ hours \\
\hline & & 3 & 13 & 7 & 7 \\
\hline \multirow[t]{2}{*}{4.} & \multirow{2}{*}{$\begin{array}{l}\text { Do you read printed } \\
\text { text materials? }\end{array}$} & \multicolumn{2}{|c|}{ Yes } & \multicolumn{2}{|c|}{ No } \\
\hline & & \multicolumn{2}{|c|}{12} & \multicolumn{2}{|c|}{18} \\
\hline \multirow[t]{2}{*}{5.} & \multirow{2}{*}{$\begin{array}{l}\text { Do you read non- } \\
\text { printed text } \\
\text { materials? }\end{array}$} & \multicolumn{2}{|c|}{ Yes } & \multicolumn{2}{|c|}{ No } \\
\hline & & \multicolumn{2}{|c|}{15} & \multicolumn{2}{|c|}{15} \\
\hline \multirow[t]{2}{*}{6.} & \multirow{2}{*}{$\begin{array}{l}\text { Do you know about } \\
\text { digital reading? }\end{array}$} & \multicolumn{2}{|c|}{ Yes } & \multicolumn{2}{|c|}{ No } \\
\hline & & \multicolumn{2}{|c|}{9} & \multicolumn{2}{|c|}{21} \\
\hline \multirow[t]{2}{*}{7.} & \multirow{2}{*}{$\begin{array}{l}\text { How many hour(s) } \\
\text { do you spend } \\
\text { reading on screen } \\
\text { daily? }\end{array}$} & $<1$ hour & $1-2$ hours & $2-4$ hours & $>4$ hours \\
\hline & & 2 & 14 & 7 & 7 \\
\hline \multirow[t]{2}{*}{8.} & \multirow{2}{*}{$\begin{array}{l}\text { What kind of digital } \\
\text { reading materials } \\
\text { have you ever used? }\end{array}$} & e-book & $\begin{array}{l}\text { Powerpoint } \\
\text { presentation }\end{array}$ & e-mail & others \\
\hline & & 4 & 7 & 4 & 15 \\
\hline \multirow[t]{2}{*}{9.} & \multirow{2}{*}{$\begin{array}{l}\text { What tools do you } \\
\text { use for on screen } \\
\text { reading? }\end{array}$} & computer & Television & $\begin{array}{l}\text { mobile } \\
\text { phone }\end{array}$ & others \\
\hline & & 9 & 4 & 12 & 5 \\
\hline \multirow[t]{2}{*}{10.} & If the reading text is & & ital & Pril & \\
\hline & $\begin{array}{l}\text { in English, which do } \\
\text { you prefer? }\end{array}$ & & & & \\
\hline
\end{tabular}

Table 1. Participants' responses on usage of technology

\section{Interview transcriptions}

The interview session was conducted after their fifth ESL lessons. Ten participants were randomly selected to be interviewed. Based on the interview, the researcher managed to get detailed personal views and opinions which help in answering the research questions. The themes were outlined and evidenced with the participants' transcription.

\section{Digital reading helps the pupils to read in English.}

Most of the participants believe that digital reading has improved their reading skills in English. With the advancement of technology in reading tools and materials, they think reading has been made easy and fun. Their views were recorded and transcribed.

"I think I like on screen reading more than printed as I can easily access the online dictionary whenever I need to find the meaning for difficult words. It helps me a lot in managing my reading strategies - from skimming, scanning and so on. However, I might be distracted after some time." (Alisa)

"Digital reading is so much fun as compared to the conventional book reading. I do not have to carry thick, heavy books anymore. And I just love how everything is on my fingertips now." (Izham)

The theme was evidenced in the interview session as most participants think digital reading benefits them in many ways. Data collected from the survey indicated that in the beginning of the research, participants were not aware of the term 'digital reading'. Item 6 in the questionnaires resulted in only 9 participants stated that they know what digital reading is. However, after their fifth session using it, the remarks made by the interviewees shows they are looking forward and interested in digital reading despite the limited time spent during ESL lessons. This finding has led to the conclusion that pupils find digital reading beneficial and meaningful in their language learning. 
The constraint of accessibility and learning opportunities using digital reading is due to poor and inadequate facilities provided by the authority.

A reading lesson with digital text excites the participants as they love interactive materials and active learning tools. As the researcher conducted ESL lessons, it is learnt that the lesson must be carried out in the multimedia room in which requires her to book the room first before using it. However, with limited accessibility and learning opportunities, the participants feel they have less exposure to digital reading in school. Their responses were recorded and transcribed as follows.

"We can go to the multimedia room, once in a week. I think English lessons would be better if we can use the room more often. It is boring to be in class, reading from the textbook." (Amsyar)

"I want to read the comprehension text from the tablet, but the teacher says most of them are damaged. We can only read digital texts on the big screen." (Husna)

The theme was further elaborated in item 9 of the questionnaire where 12 participants stated that they use mobile phones in digital reading, most probably when they are at home. This further explain the drawback of using technology in reading lessons as it requires the teacher and learners to be fully equipped with adequate learning tools and materials. Based on the findings and triangulation of data, it is evidenced that the result of the study has fulfilled the aim and answered the research question.

\section{Conclusions}

The research findings have provided some important implications to the learners and educators at large. Most of the pupils agree that digital reading help them in ESL reading lessons as it provides them better learning experiences. Learners are able to enjoy fun and interactive reading lessons provided in virtual websites and platforms. It enhances their reading skill by adding more learning features like online dictionary, reading tools and other learning media. As the country is moving towards 21 st century learning, teachers need to be aware of the positive and negative impact that this digital reading brings. With easy access and everything is just at one click, it can benefit the learners in saving time and space. Low cost and wide range of online texts offered are becoming the advantages of digital literacy.

Despite the benefits offered, pupils find digital reading as a limitation to be conducted during the lessons due to the lack of adequate learning facilities provided in school. It has made it one of the major constraints in using digital reading during ESL lessons. With the misuse of the invention in the technology advancement, it may lead to increasing number of readers having difficulties in focusing on the text online. The high-tech features built in digital tools has become the wasted luxury as they are distractions to comprehending the text. Lack of training in utilizing the tools has also created a distinction gap which tells the educators are not fully ready to include digital reading in their lesson.

It is best to further explore the area in depth as to fulfill the aspiration of Malaysian education curriculum; to prepare the learners with 21st century skills in bilingual competency. (Ministry of Education, 2013). As long as the content is clearly delivered, both digital and printed texts have their own roles in improving literacy, especially in reading.

\section{References}

Baron, N. S. 2017. Reading in a digital age. Phi Delta Kappan, 99(2), 15-20

Chuttur M.Y. 2009. Overview of the Technology Acceptance Model: Origins, Developments and Future Directions. Indiana University, USA . Sprouts: Working Papers on Information Systems, 9(37)

Ciampa, Katia. 2016. Implementing a Digital Reading and Writing Workshop Model for Content Literacy Instruction in an Urban Elementary (K-8 School). The Reading Teacher Vol. $70 \quad$ No. $3 \quad$ pp. 295-306

Dobler, Elizabeth. 2015. E-Textbooks: A Personalized Learning Experience or A Digital Distraction? Journal of Adolescent \& Adult Literacy. 58(6) March 2015

Gartner Inc. 2011. Gartner survey shows digital text consumption nearly equal to time spent reading printedop paper text. http://www.gartner.com/newsroom/id/1673714

Harris, L. R. \& Brown, G. T. L. 2010. Mixing interview and questionnaire methods: Practical problems in aligning data. https://pareonline.net/Pdf/V15n1.Pdf

Hashim, H., Md. Yunus, M., Embi, M. A., Mohamed Ozir, N. A. 2017. Mobile-assisted

Language Learning (MALL) for ESL Learners: A Review of Affordances and Constraints. https://sainshumanika.utm.my/index.php/sainshumanika/article/view/1175/699

Hashim, H. \& Md. Yunus, M. 2012. Tell Me More : Issues and Challenges. 
Using digital reading in ESL Malaysian primary classrooms : the strengths and the shortcomings from the learners' perspectives

http://www.journals.aiac.org.au/index.php/alls/article/view/60/57

Hashimoto, Y. (Ed.). 2011. Nihonjin no jyouhou koudou 2010. Tokyo: University of Tokyo Press. [In Japanese.]

Lauren M. Singer \& Patricia A. Alexander. 2017. Reading Across Mediums: Effects of Reading Digital and Print Texts on Comprehension and Calibration. The Journal of Experimental Education, 85:1, 155-17

Masrom, Maslin. 2007. Technology Acceptance Model and E-learning. 12th International Conference on Education, Sultan Hassanal Bolkiah Institute of Education Universiti Brunei Darussalam

Ministry of Education. 2013. Malaysian Education Blueprint 2013-2025. Kementerian Pendidikan Malaysia.

Morshidi, A., Embi, M. A., \& Hashim, H. 2019. Instagram Application: An Active Tool in Cultivating Reading Behaviour. Journal of Information System and Technology Management, 4(11), 95106.

Nor Pazilah, F., Hashim, H., \& Md. Yunus, M. 2019. Using Technology in ESL Classroom. https://www.scirp.org/pdf/ce_2019112915161491.pdf

Razali, M. A., Hashim, H. \& Md. Yunus, M. 2019. Beyond ESL Classroom: The Use of MOOC in Enhancing ESL Reading Skills. https://iopscience.iop.org/article/10.1088/1742-6596/1424/1/012032/pdf

Surendran, Priyanka. n.d. Technology Acceptance Model : A Survey of Literature. http://thejournalofbusiness.org/index.php/site/article/view/161

Syaputri, K. D. \& Trilestari, K. 2017. A Survey of Readers' Reading Preference: Digital or Printed Reading Text. http://eprints.binadarma.ac.id/3563/1/A\%20Survey\%20of\%20Readers\%E2\%80\%99\%20Reading\%20 Preference\%2C\%20Digita1\%20or\%20Printed\%20Text.pdf 